\title{
Genomic and Functional Characterization of the Endophytic Bacillus subtilis 7PJ-16 Strain, a Potential Biocontrol Agent of Mulberry Fruit Sclerotiniose
}

\section{Author: Wei-Fang, Hui-Shuang Ren, Ting Ou, Ting Lei, Jun-Hong Wei, Chuan-Shu Huang, Tian Li, Gary A. Strobel, Ze-Yang Zhou, and Jie Xie}

The final publication is available at Springer via http://dx.doi.org/10.1007/s00248-018-1247-4.

Xu, Wei-Fang, Hui-Shuang Ren, Ting Ou, Ting Lei, Jun-Hong Wei, Chuan-Shu Huang, Tian Li, Gary Strobel, Ze-Yang Zhou, and Jie Xie. "Genomic and Functional Characterization of the Endophytic Bacillus subtilis 7PJ-16 Strain, a Potential Biocontrol Agent of Mulberry Fruit Sclerotiniose." Microbial Ecology (September 2018): 1-13. DOI:10.1007/s00248-018-1247-4. 
Genomic and Functional Characterization of the Endophytic Bacillus subtilis 7PJ-16 Strain, a Potential Biocontrol Agent of Mulberry Fruit Sclerotiniose

Wei-fang $\mathrm{Xu}^{1,2} \cdot$ Hui-shuang $\operatorname{Ren}^{1,2} \cdot$ Ting $\mathrm{Ou}^{1,2} \cdot$ Ting $\mathrm{Lei}^{3} \cdot$ Jun-hong Wei 1,2 Chuan-shu Huang ${ }^{3}$ Tian Li ${ }^{1,2} \cdot$ Gary Strobel $^{4} \cdot$ Ze-yang Zhou ${ }^{1,2,5} \cdot$ Jie Xie $^{1,2}$

${ }^{1}$ State Key Laboratory of Silkworm Genome Biology, College of Biotechnology, Southwest University, Chongqing 400715, PR China

${ }^{2}$ Key Laboratory of Sericultural Biology and Genetic Breeding, Ministry of Agriculture, College of Biotechnology, Southwest University, Chongqing 400715, PR China

${ }^{3}$ Institute of Sericulture Science and Technology Research, Chongqing 400700, PR China

${ }^{4}$ Department of Plant Sciences, Montana State University, Bozeman, MT 59717, USA

${ }^{5}$ College of Life Science, Chongqing Normal University, Chongqing 400047, PR China

Author for correspondence: zyzhou@swu.edu.cn (Ze-yang Zhou); healthjie@163.com (Jie $\mathrm{Xie})$ 


\section{Abstract}

Bacillus sp. 7PJ-16, an endophytic bacterium isolated from healthy mulberry stems and previously identified as Bacillus tequilensis 7PJ-16, exhibits strong antifungal activity and the capacity to promote plant growth. This strain was studied for its effectiveness as a biocontrol agent to reduce mulberry fruit sclerotiniose in the field and as a growth-promoting agent for mulberry in the greenhouse. In field studies, the cell suspension and supernatant of strain 7PJ-16 exhibited biocontrol efficacy and the lowest disease incidence was reduced down to only $0.80 \%$. In greenhouse experiments, the cell suspension $\left(1.0 \times 10^{6}\right.$ and $\left.1.0 \times 10^{5} \mathrm{CFU} / \mathrm{mL}\right)$ and the cell-free supernatant (100-fold and 1000-fold dilution) stimulated mulberry seed germination and promoted mulberry seedling growth. In addition, to accurately identify the 7PJ-16 strain and further explore the mechanisms of its antifungal and growth-promoting properties, the complete genome of this strain was sequenced and annotated. The 7PJ-16 genome is comprised of two circular plasmids and a 4,209,045 bp circular chromosome, containing 4,492 protein-coding genes and 116 RNA genes. This strain was ultimately designated as Bacillus subtilis based on core genome sequence analyses using a phylogenomic approach. In this genome, we identified a series of gene clusters that function in the synthesis of non-ribosomal peptides (surfactin, fengycin, bacillibactin and bacilysin) as well as the ribosome-dependent synthesis of tasA and bacteriocins (subtilin, subtilosin A), which are responsible for the biosynthesis of numerous antimicrobial metabolites. Additionally, several genes with function that promote plant growth, such as indole-3-acetic acid biosynthesis, the production of volatile substances, and siderophores synthesis, were also identified. 
The information described in this study established a good foundation for understanding the beneficial interactions between endophytes and host plants, and facilitates the further application of $B$. subtilis $7 \mathrm{PJ}-16$ as an agricultural biofertilizer and biocontrol agent.

\section{Keywords}

Bacillus subtilis · Control efficiency · Plant growth promotion · Genome sequence $\cdot$ Antimicrobial metabolites 


\section{Introduction}

Mulberry sclerotiniose, also known as white fruit disease, is a widespread destructive disease of mulberry fruit that is responsible for huge economic losses each year $[1,2]$. The disease is divided into three types distinguished by the symptoms that appear on infected fruits in association with different causal agents: 1) mulberry sorosus hypertrophic sclerote disease, 2) mulberry sorosus parvulling sclerote disease, and 3) mulberry sorosus diminuting sclerote disease [3]. The first type is the most common both in China and in other parts of the world $[4,5]$. There are four species in the family Sclerotiniaceae that have been implicated in these three types of symptoms: Ciboria shiraiana [6, 7], Ciboria carunculoides [8, 9], Sclerotinia sclerotiorum [4] and Scleromitrula shiraiana [6], each of which can infect mulberry fruit. In recent decades, chemical and non-chemical treatments have been successfully used to control the fruit disease [10,11], and most reports described chemical interventions. Unfortunately, the long-term overuse of chemical pesticides has many side-effects on environmental safety and the balance of the agroecosystem. Furthermore, human health is potentially threatened by the presence of fungicide residues in fruits. Therefore, biological control of plant pathogens through the application of antagonistic probiotics is a promising plant protection strategy because it is safe for human beings and is environmentally friendly $[12,13]$.

Bacillus is a large, heterogeneous group of gram-positive, rod-shaped, endospore-forming aerobic or facultatively anaerobic bacteria that are able to grow in various environments, including plant tissues [14]. Many different communities of 
Bacillus spp. have been isolated from a variety of plant hosts such as maize [15], mulberry [16], and rice [17]. The endophytic Bacillus species, especially Bacillus subtilis, suppress phytopathogenic fungal growth by producing a variety of bioactive compounds, with $4 \sim 5 \%$ of the bacterial genome being dedicated to the synthesis of these antimicrobial compounds [18]. Among these bioactive substances, cyclic lipopeptides (CLPS), non-ribosomally synthesized peptide derivatives, play an important role in antagonizing phytopathogen growth. Furthermore, some strains of $B$. subtilis enhance plant nutrition and stimulate plant growth while colonizing the tissues of the host plant [19].

The genus Bacillus is genetically diverse, so it has been difficult to classify Bacillus species accurately thus far, such as the taxonomy of the B. subtilis-like organisms B. subtilis and Bacillus tequilensis [20]. The analysis of 16S rRNA gene sequences is currently the most commonly used method for bacterial identification, but its usefulness is limited due to the high similarity among related taxa [21]. Recently, genome comparisons and phylogenomic analyses have been common approaches for the reconfirmation of some Bacillus species [22].

Previously, we isolated and identified an endophytic bacterium Bacillus sp. 7PJ-16, originally classified as B. tequilensis based on comprehensive analysis of its morphological, physiological, biochemical and 16S rRNA gene sequence characteristics (accession numbers, KR708875) [23]. However, 16S rRNA analysis of the 7PJ-16 strain also revealed a similarity of $\geq 99 \%$ to several B. subtilis isolates (e.g., accession numbers NR113265, NR112629 and NR027552.) deposited in NCBI. 
Therefore, further experimental verification was needed for the taxonomic clarification of our 7PJ-16 strain. The 7PJ-16 strain exhibited strong antagonistic activity against various plant pathogens, including S. shiraiana, S. sclerotiorum, Botryotinia fuckeliana, Cercospora beticola, and Fusarium oxysporum, and cell-free supernatant of 7PJ-16 promoted mulberry tissue culture seedlings growth [23]. Our previous work revealed that the 7PJ-16 isolate is a promising biocontrol agent for mulberry fruit sclerotiniose, but its mechanisms of antimicrobial and growth-promoting properties remained to be explored. The aims of this study were (i) to evaluate the biocontrol efficiency of Bacillus sp. 7PJ-16 for mulberry fruit sclerotiniose in the field; (ii) to assess the growth-promoting ability of this strain in greenhouse conditions; (iii) to confirm the taxonomy of the 7PJ-16 strain using phylogenomic analysis and subsequently detect genes or gene clusters encoding secondary metabolites by sequencing and genome annotation of Bacillus sp. 7PJ-16; and (iv) to determine the potential of Bacillus sp. 7PJ-16 for secondary metabolite production. Ultimately, the goal is to have enough solid scientific information to the application of 7PJ-16 strain in the biological control mulberry fruit sclerotiniose.

\section{Materials and Methods}

\section{Bacterial Strain and the Culture Medium}

The 7PJ-16 strain was originally isolated from the surface-sterilized stem of a healthy Chuan Sang 7637 (mulberry cultivar which tolerant to mulberry fruit sclerotiniose) sampled from the mulberry experimental field of the Sericulture Science and Technology Institute, Chongqing, China $\left(29^{\circ} 50^{\prime} 39^{\prime \prime} \mathrm{N}, 106^{\circ} 25^{\prime} 55^{\prime \prime} \mathrm{E}\right)$ 
[23]. It was stored at $-80{ }^{\circ} \mathrm{C}$ in $30 \%$ glycerol. The bacterial cells were streaked onto LB agar plates, and a single colony was inoculated into LB broth $(100 \mathrm{~mL}$ in a 250 mL Erlenmeyer flask) with constant shaking at 180 revolutions per minute (rpm) at 28 ${ }^{\circ} \mathrm{C}$ for $18 \mathrm{~h}$ before using.

\section{Determination of the 7PJ-16 Strain Biocontrol Properties in the Field}

Fresh Bacillus sp. 7PJ-16 cultures were obtained as described above, and then they were inoculated into modified potato dextrose broth (PDB) for bioactive compounds production (1\% v/v, inoculation amount) (MPDB medium, $200 \mathrm{~g}$ potato, $20 \mathrm{~g}$ maltose, $10 \mathrm{~g}$ peptone, $5 \mathrm{~g}\left(\mathrm{NH}_{4}\right)_{2} \mathrm{SO}_{4}, 1.5 \mathrm{~g} \mathrm{Na}_{2} \mathrm{HPO}_{4}$ per liter) and incubated at $30{ }^{\circ} \mathrm{C}$ for 4 days in a fermentation tank (300 rpm). The bacterial cultures were centrifuged at $8,000 \mathrm{rpm}$ for $20 \mathrm{~min}$ to generate the supernatant. On the other hand, Bacillus sp. 7PJ-16 was incubated in PDB for $18 \sim 24 \mathrm{~h}$, and then the cultures were centrifuged at 5,000 rpm for $8 \mathrm{~min}$, finally the bacterial pellets were resuspended in sterilized distilled water (SDW). Fresh prepared cell suspension were adjusted to 1.0 $\times 10^{9}, 1.0 \times 10^{8}$ and $1.0 \times 10^{7}$ colony forming units per microliter $(\mathrm{CFU} / \mathrm{mL})$ with SDW and the supernatant were diluted in SDW as original, 10-fold and 100-fold dilution before being applied in the field experiments.

The field experiments were performed at the Sericulture Science and Technology Institute, Chongqing, China $\left(29^{\circ} 50^{\prime} 39^{\prime \prime} \mathrm{N}, 106^{\circ} 25^{\prime} 55^{\prime \prime}\right.$ E) during the spring of two consecutive years (2016 and 2017) using mulberry cultivar Morus atropurpurea Roxb cv. ' Zhongsang 5801'. It has been known for the past 5 years that the orchard was naturally infested, and sclerotium and apothecia were also found in 
the orchard. There are $1 \mathrm{~m}$ separation belts between different experimental plots and the size of each plot was about $4 \times 10 \mathrm{~m}$. Approximately $36 \sim 42$ plants were grown in each plot.

In 2016, the experiment consisted of four treatments: (1) water control; (2) fungicide thiophanate-methyl (1000-fold dilution); (3) Bacillus sp. 7PJ-16 supernatant (original) and (4) Bacillus sp. 7PJ-16 supernatant (100-fold dilution). All treatments were applied three times at the initial, full and end of flowering stage, respectively. In 2017, the biocontrol effects of Bacillus sp. 7PJ-16 bacterial suspension and supernatant were evaluated, and the effects of different application time and various treatment concentration on disease incidence of mulberry fruits were also assessed. The following sixteen treatments were included in this experiment (1) water control; (2) application of the fungicide thiophanate-methyl (1000-fold dilution) three times at the initial, full and end of flowering stage respectively; (3)-(5) application of the 7PJ-16 cell suspension at the initial flowering stage with three concentrations which were $1.0 \times 10^{9}, 1.0 \times 10^{8}$ and $1.0 \times 10^{7} \mathrm{CFU} / \mathrm{mL}$ respectively; (6)-(8) 7PJ-16 cell suspension was applied twice (at the initial and full flowering stage) with three concentrations which were $1.0 \times 10^{9}, 1.0 \times 10^{8}$ and $1.0 \times 10^{7} \mathrm{CFU} / \mathrm{mL}$ respectively; (9) 7PJ-16 cell suspension of $1.0 \times 10^{9} \mathrm{CFU} / \mathrm{mL}$ was applied three times at the initial, full and end of flowering stage respectively; (10)-(12) 7PJ-16 supernatant of three different dilutions (original, 10-fold and 100-fold dilution) were applied at the initial flowering stage; (13)-(15) 7PJ-16 supernatant of three different dilutions (original, 10-fold and 100-fold dilution) were applied twice at the initial and full flowering 
stage respectively; (16) applications of original 7PJ-16 supernatant three times at the initial, full and end of flowering stage respectively. The 7PJ-16 supernatant was collected after being cultured in MPDB medium for $48 \mathrm{~h}$. All treatments were applied at 9:00-10:00 AM. As for all treatments applied three times, included all treatments in 2016 and treatments (1), (2), (9) and (16) in 2017, a randomized block design with 3 replicates (12 trees per replicate) of each treatment was performed, rather than 3 replicates ( 3 trees per replicate) of each treatment for other treatments.

The disease incidence of mulberry fruits was investigated approximately one week before harvest. For each treatment, the total and diseased fruits from three independent trees (two or three branches per tree) were visually recorded. The disease incidence of each treatment was calculated as the percentage of diseased fruits. The disease incidence and biocontrol efficacy of each treatment were calculated as follows:

Disease incidence $(\%)=$ the number of diseased fruits / the total number of fruits examined $\times 100$;

Control efficacy $(\%)=($ the mean disease incidence of the control - the mean disease incidence of the treatment) / the mean disease incidence of the control $\times 100$.

\section{Effects of the 7PJ-16 Strain on Mulberry Seed Germination and Seedling}

\section{Growth}

Fresh cell suspension and cell-free supernatant of 7PJ-16 strain were prepared as described above in the King's B medium [24] rather than MPDB or normal PDB medium, and the cell-free supernatant in this section was obtained by being passed 
through $0.22 \mu \mathrm{m}$ micropore filter. Different concentrations of 7PJ-16 cell-free supernatant (original, 10-fold, 100-fold and 1000-fold dilution) and different concentrations of 7PJ-16 suspension $\left(1.0 \times 10^{8}, 1.0 \times 10^{7}, 1.0 \times 10^{6}\right.$ and $1.0 \times 10^{5}$ $\mathrm{CFU} / \mathrm{mL}$ ) were diluted in SWD.

Mulberry seeds (Gui Sangyou No.12) were disinfected and germinated according to the methods described by Xie et al. [25]. Briefly, the surface-disinfected seeds were respectively soaked in 7PJ-16 cell-free supernatant of different dilutions and 7PJ-16 cell suspension of different cell concentrations for $24 \mathrm{~h}$ at $25{ }^{\circ} \mathrm{C}$. The treated seeds were eventually germinated on sterile moist filter paper in Petri dishes at $26{ }^{\circ} \mathrm{C}$ for 15 days with $12 \mathrm{~h}$ of light. On the fourth day of cultivation, the germination potential was calculated as the percentage of germinated mulberry seeds. The seed germination rate was recorded at the eighth day. Furthermore, the length of plumule and radicle were measured after the seedlings were cultivated for 15 days. Surface-disinfected seeds treated with King's B medium and SWD were served as controls. Each treatment was replicated three times with 20 seeds apiece.

The seedlings used for pot experiments were obtained using the water-treatment seed germination described above. The seedlings were aseptically transplanted into 8 $\times 8 \mathrm{~cm}$ diameter pots containing autoclaved soil, and planted $3 \sim 4$ seedlings in each pot. And then all seedlings were cultivated in a greenhouse at $28{ }^{\circ} \mathrm{C}$, relative humidity $70 \%$, and a $12 \mathrm{~h}$ photoperiod. When the seedling grew to 4 leaves, $10 \mathrm{~mL}$ of each treatment samples were applied to one pot. Each treatment was replicated three times. Forty five days after inoculation, five seedlings were randomly selected from each 
treatment to measure parameters of plant growth, including root and shoot length, fresh weight of root and shoot, and dry weight of root and shoot.

\section{Statistical Analysis}

All treatments for each experiment were compared using analysis of one-way analysis of variance (ANOVA), and the means were compared using a least significant difference (LSD) test at $\mathrm{P} \leq 0.05$. The program Excel and SPSS, version 17.0 (SPSS Inc., Chicago, IL, USA) were used for statistical analysis.

\section{Genomic DNA Preparation, Sequencing and Analysis}

The 7PJ-16 strain was cultured in LB medium as described above, and bacterial cells were subsequently collected via centrifugation. Genomic DNA was extracted with Prepman Ultra Sample Preparation Reagent (Applied Biosystems, USA) according to the manufacturer's instructions. The entire genome of 7PJ-16 was examined on a Pacific Biosciences RSII sequencer (PacBio, Menlo Park, CA) according to standard protocols at Guangzhou Genedenovo Biotechnology Co., Ltd. (Guangdong, China).

De novo sequence assembly of the genome was performed using the software hierarchical genome-assembly process (HGAP) [26]. The open reading frame was predicted using GeneMarkS [27], which is a well-studied gene-finding program used for prokaryotic genome annotation. The protein sequences were annotated based on observed genes and searched using various function-related databases (Clusters of Orthologous Groups, COG; Kyoto Encyclopedia of Genes and Genomes, KEGG; Non-Redundant Protein Database, Nr; and Gene Ontology, GO). A circular genome 
map with COG functional annotation was plotted with Circos [28]. The phylogenetic tree based on the core genomes of 18 strains with known genome sequences related to members of the Bacillus genus was constructed using MEGA 6.0 software using the neighbor-joining method and default parameters [29]. Bioactive secondary $\begin{array}{lllll}\text { metabolites } & \text { were } & \text { predicted } & \text { with } & \text { antiSMASH }\end{array}$ (http://antismash.secondarymetabolites.org/\#!/start).

\section{Production of Secondary Metabolites}

The production of siderophores, cellulase and volatile compounds was detected on standard chrome Azurol-S (CAS) agar medium [30], carboxymethylcellulose agar medium [31] and a two-compartment Petri dish [32], respectively. The qualitative detection of indole acetic acid was inferred by the methods of Jasim, Joseph \& John $[30]$.

\section{Results}

\section{Biocontrol Efficacies of 7PJ-16 on Mulberry Fruit Sclerotiniose in the Fields}

In the 2016 experiment, the disease incidence for the 7PJ-16 supernatant treatment, regardless of original $(19.57 \%)$ or 100 -fold dilution $(52.83 \%)$, were much lower than that of the water control $(70.22 \%)$ (Table 1$)$. The biocontrol efficacy of the original 7PJ-16 supernatant was up to $72.13 \%$, although it was lower than that of the fungicide treatment $(98.16 \%)$ (Table 1). Whereas, when original 7PJ-16 supernatant was applied twice on the mulberry flowers, the leaves were decrescent and slightly curled, and the flowers were marginally withered. Interestingly, these leaf and flower disease symptoms were not observed in the mature fruit stage. The phenomenon 
might suggest that the original 7PJ-16 supernatant, collected on 4 days after inoculation, contained high concentration of antibiotics, and they can effectively suppress phytopathogen growth but with obviously negative effects on mulberry. Thus, the fermentation time of harvesting 7PJ-16 supernatant was adjusted to 2 days in the field experiment of 2017, which might decrease the concentration of antibiotics.

The field experimental results in 2017 indicated 7PJ-16 cell suspension or supernatant could control the disease incidence of mulberry fruit sclerotiniose, but the biocontrol efficacy decreased gradually when the 7PJ-16 cell suspension or supernatant were diluted and the application times were shortened (Table 2). The biocontrol efficacy of the 7PJ-16 cell suspension of $1.0 \times 10^{9} \mathrm{CFU} / \mathrm{mL}$ (original) was equivalent to the original 7PJ-16 supernatant regardless of application times: one application (84.33\% vs $85.88 \%)$, two applications (87.33\% vs $87.99 \%)$ and three applications (90.84\% vs $87.78 \%$ ), respectively (Table 2). Additionally, applying $7 \mathrm{PJ}-16$ cell suspension of $1.0 \times 10^{9} \mathrm{CFU} / \mathrm{mL}$ three times resulted in the lowest disease incidence $(0.80 \%)$, performing better than that of the fungicide $(0.83 \%)$. Interestingly, as for the treatments applied three times, the fruits which were treated with the 7PJ-16 cell suspension of $1.0 \times 10^{9} \mathrm{CFU} / \mathrm{mL}$ matured earlier no matter turned red or finally matured compared with the other treatments (Fig. 1A). Meanwhile, mulberry trees treated with the 7PJ-16 supernatant had the same growth in comparison with other treatments, without any phytotoxicity symptoms (Fig. 1C). Additionally, the 7PJ-16 cell suspension of $1.0 \times 10^{9} \mathrm{CFU} / \mathrm{mL}$ could accelerate the ripening of mulberry fruits. This observation prompted us to evaluate its capacity of plant growth promotion on 
mulberry seed and seedling in greenhouse conditions.

\section{Growth-Promotin Assay of 7PJ-16 on Mulberry Seed Germination and} Mulberry Seedling Growth in Greenhouse Conditions

Compared with the two control treatments, the 7PJ-16 cell suspension of $1.0 \times$ $10^{5} \mathrm{CFU} / \mathrm{mL}$ and the $7 \mathrm{PJ}-16$ cell-free supernatant of 1000 -fold dilution significantly $(\mathrm{P} \leqslant 0.05)$ increased the germination potential and germination rate of mulberry seeds (Table 3). The seeds treated with the cell-free supernatant (original and 10-fold dilution) or cell suspension of $1.0 \times 10^{7} \mathrm{CFU} / \mathrm{mL}$ did not seem to stimulate mulberry seeds germination. In addition, the seedlings in the all treatments of the 7PJ-16 cell-free supernatant exhibited longer plumule length and radicle length than those for treatments of the 7PJ-16 cell suspension, and the most striking effect was observed in the treatment with 7PJ-16 cell-free supernatant at a 10-fold dilution. It resulted in an remarkably increase radicle length from $30.18 \mathrm{~mm}$ to $43.71 \mathrm{~mm}$ and promoted the plumule length from $11.10 \mathrm{~mm}$ to 15.26 as compared with the water control (Table 3).

The 7PJ-16 suspension greatly promoted mulberry seedlings growth, especially the treatment with the $7 \mathrm{PJ}-16$ cell suspension of $1.0 \times 10^{6} \mathrm{CFU} / \mathrm{mL}$. All growth parameters, including the root length, the shoot length and the fresh/dry weight of root and shoot of seedlings, were significantly $(\mathrm{P} \leqslant 0.05)$ higher in this treatment compared to those of water control (CK) plants (Fig. 2 and Fig. S1). Notably, compared with the $\mathrm{CK}$, this treatment increased root length from $2.22 \mathrm{~mm}$ to $4.14 \mathrm{~mm}$ (Fig. 2A), and increased shoot fresh weight from $55.18 \mathrm{mg}$ to $128.82 \mathrm{mg}$ (Fig. 2B). Furthermore, the $1.0 \times 10^{5} \mathrm{CFU} / \mathrm{mL}$ suspension also facilitated root growth in comparison with the $\mathrm{CK}$, 
as the dry weight of these seedlings increased by $120.39 \%$ (from $1.52 \mathrm{mg}$ to $3.35 \mathrm{mg}$ ) (Fig. 2C).

Similarly, the 7PJ-16 cell-free supernatant also partly stimulated the growth of mulberry seedlings, particularly the treatment with a 100-fold dilution of 7PJ-16 supernatant, which clearly enhanced root length from $2.08 \mathrm{~mm}$ to $4.01 \mathrm{~mm}$ compared to the water control (Fig. 2D). However, the original cell-free supernatant produced a slightly negative effect on the growth of mulberry seedlings. The shoot length, root fresh weight and shoot fresh weight of plants grown in this treatment decreased by 4.17\%, 5.26\%, and 11.42\%, respectively (Fig. 2D, E and Fig. S2).

\section{Genome Sequencing and Phylogenetic Analysis of Bacillus sp. 7PJ-16}

The complete genome of Bacillus sp. 7PJ-16 consists of a 4,209,045 bp circular chromosome and two circular plasmids unnamed $1(21,679 \mathrm{bp})$ and unnamed $2(8,581$ bp) (Fig. 3). The $\mathrm{G}+\mathrm{C}$ contents of the chromosome and the two plasmids are $43.28 \%$, $40.30 \%$ and $38.54 \%$, respectively. The chromosome contains 4,492 predicted coding sequences (CDSs), 30 rRNA genes and 86 tRNA genes; the two plasmids contain 29 and 12 predicted CDSs, respectively (Fig. 3).

The general features of Bacillus sp. 7PJ-16 genome and other representative Bacillus strains are summarized in Table 4. Phylogenetic analysis revealed that 7PJ-16 forms a distinct branch with B. subtilis Bsn5 (CP002468), B. subtilis SG6 (CP009796), B. subtilis QB928 (CP003783) and B. subtilis subsp.subtilis str.168 (NC_000964) (Fig. 4), which suggested that it may be more appropriately identified as a B. subtilis strain. To confirm this hypothesis, we performed a BLAST search on the sequence of the 
gryA gene of the subject strain (data not given), which this gene can be used to differentiate B. subtilis and related Bacillus species [33]. The BLAST search indicated that Bacillus sp. 7PJ-16 has a greater than $99 \%$ sequence similarity to several $B$. subtilis isolates (accession numbers AY663694 and EU138617) rather than $B$. tequilensis for the gryA gene sequence. Therefore, we propose that Bacillus sp. 7PJ-16 be recognized as a strain of $B$. subtilis, as an update to its final classification status [23].

\section{Secondary Metabolite Gene Clusters in B. subtilis 7PJ-16}

Genome analysis revealed that there are two different pathways for the biosynthesis of secondary metabolites in the B. subtilis 7PJ-16 genome. This strain harbors ten gene clusters related to antimicrobial activities (Table 5). Among these gene clusters, four are related to non-ribosomal peptide synthetases including surfactin, fengycin, bacillibactin and bacilysin, covering over $213.7 \mathrm{~kb}$ in total. Additionally, two of the gene clusters direct the synthesis of the bacteriocins, subtilin and subtilosin A, which mainly inhibit the growth of similar or closely related bacterial strains. In contrast to other closely related strains, the $\operatorname{tas} A$ gene was also found.

Surfactin has been reported to be a cyclic lipopeptide antibiotic with a strong inhibitory effect on tumors, viruses and mycoplasma [34]. The biosynthesis of surfactin in B. subtilis 7PJ-16 was attributed to a large $65.4 \mathrm{~kb}$ DNA sequence, consisting of four core biosynthetic genes ( $\operatorname{srfABCD}$ ) and four additional transport-related genes $(y c x A B C D)$. Fengycin and the closely related plipastatin are 
also CLPs, which are specifically active against filamentous fungi [35]. The pps operon was assigned to fengycin biosynthesis, but $B$. subtilis 7PJ-16 only has partial genes (ppsE, ppsD) in this gene cluster. A similarly incomplete fengycin cluster was previously discovered in Bacillus amyloliquefaciens DSM-7 [36]. Bacilysin, one of the simplest known peptide antibiotics, is active against a variety of bacteria and the yeast Candida albicans [37]. In addition, the functional bacABCDE gene cluster responsible for bacilysin synthesis was detected in the 7PJ-16 genome. Additionally, B. subtilis $7 \mathrm{PJ}-16$ also might be an excellent bacteriocin producer, potentially producing two common lantipeptides, subtilin and subtilosin A, which are capable of inhibiting the growth of gram-positive bacteria [38]. Notably, we also found the tas $A$ gene from the coding region, and it can express an antimicrobial protein which has a significant antagonistic effect on numerous phytopathogens [39].

Identification of Genetic Elements in B. subtilis 7PJ-16 Associated With the Promotion of Plant Growth

In addition to the diverse genes related to antimicrobial metabolites, strain 7PJ-16 also harbors genes involved in the synthesis of various substances that promote plant growth, including auxin (e.g., IAA), bacillibactin and volatile compounds (e.g., 2,3-butanediol and acetoin) (Table 6). Bacillibactin, an iron-siderophore encoded by the $d h b$ gene cluster, can help Bacillus cells to take up iron ions from the natural environment under iron-limited conditions. Indole acetic acid (encoded by the $y h c X$ and dhaS genes), acetoin (encoded by the alsD, alsS and als $R$ genes) and 2,3-butanediol (encoded by the $b d h A$ gene) have been indicated to 
enhance plant growth and trigger systemic resistance [40]. Notably, the $b g l C$ and $b g l S$ genes (encoding cellulase) and $x y n A$ and $x y n D$ (encoding xylanase), which play a key role in the degradation of plant cell walls [40], were also found in the B. subtilis 7PJ-16 genome. Accordingly, the results regarding metabolite production showed that 7PJ-16 possesses the ability to secrete iron-siderophores, indole acetic acid and volatile compounds (Fig. 5).

\section{Discussion}

Compared with chemical control, biological control has been considered to be a potential and sustainable alternative method due to the rare environment pollution and low health risk. Several bacterial strains showing high antagonistic activity towards phytopathogens, such as Bacillus [17, 19, 22, 32, 41], Pseudomonads [42], and Pantoea [25] can be successfully employed as potential biocontrol agents in plant disease management. Our results of the two-year field experiments indicated that the application of 7PJ-16 was able to suppress the occurrence of mulberry fruit sclerotiniose under field conditions, even in 2016 with the high disease incidence in case of the water treatment $(70.22 \%)$ (Table 1$)$. In 2017, the biocontrol efficacies in the high-concentration treatments were better than that of the relatively low-concentration treatments, and the efficacy was affected by application times to a certain extent (Table 2). Similar results were obtained by the application of endophytic B. subtilis EDR4 controlling S. sclerotiorum on rapeseed [41]. In fact, it has been reported that the cell suspension of B. thuringiensis $\mathrm{C} 25$ and the wettable powder of Trichoderma sp. can be used to control the mulberry fruit disease in fields, 
but the disease prevention efficacy remained only at 51.98\% 84.02\% [13, 43] which was less than the control efficacy of present study (90.84\%). This paper revealed that the 7PJ-16 strain have the huge potential to control the sclerotial disease of mulberry fruit, and therefore makes itself a good candidate of biological control in modern agricultural systems.

Bacillus species produce a structurally diverse group of antimicrobial compounds, among which the three families of lipopeptides (surfactin, fengycin and iturin) exhibit highly potent antifungal activity and are very heat stable and insensitive to $\mathrm{pH}$ [44]. Numerous studies have demonstrated that the antifungal effect of Bacillus strains against phytopathogenic fungi was closely associated with lipopeptides synthesis [45-47]. Although the molecules responsible for the antagonistic activity of B. subtilis 7PJ-16 have not yet been identified, genes involved in lipopeptides synthesis, such as srfABCD, ycxABCD and ppsDE, were detected in the 7PJ-16 strain genome. Furthermore, the stability assay indicated that when the cell-free supernatant containing crude bioactive substances from the 7PJ-16 strain was subjected to different $\mathrm{pH}$ and thermal conditions, the antifungal activity was not affected [23]. Therefore, one underlying antimicrobial mechanism of the 7PJ-16 strain may be the presence of genes encoding surfactin and other lipopeptides in its genome.

Apart from controlling diseases, the genus Bacillus also directly or indirectly promote plant growth by several mechanisms, including production of phytohormones like IAA, siderophores production and secretion of the active enzymes, such as cellulose and protease $[19,48,49]$. Our pot experiment results demonstrated that $B$. 
subtilis 7PJ-16 did have positive effects on the mulberry growth, and both 7PJ-16 cell suspension and cell-free of this strain supernatant could stimulate the mulberry seed germination and mulberry seedling growth, especially for the relatively low-concentration treatments, such as the cell suspension of $1.0 \times 10^{6} \mathrm{CFU} / \mathrm{mL}$ and cell-free supernatant of 100-fold dilution (Fig. 2, Fig. 1S and Fig. 2S). Mulberry growth promotion might be related to the siderophore, cellulose, IAA and volatile compounds produced by the 7PJ-16 strain (Table 6, Fig. 5). These results indicated that the antagonistic bacterium 7PJ-16 can also serve as a plant growth stimulator or biofertilizer.

Since Bacillus species have the ability to control plant diseases and improve the plant growth by several mechanisms, these beneficial properties have resulted in the isolation, characterization and application of many strains of this organism for use in plant protection [17, 19, 41, 48]. However, many Bacillus strain have very similar phenotypic, physiological properties and 16S rRNAs gene sequences, making the definitive taxonomy of these strains very difficult [50]. Owing to the development of sequencing technique and bioinformatics, the whole genome of numerous Bacillus genus have been sequenced and some strains were re-categorized into other species by the genome phylogenomic analysis $[22,51]$. The final classification status as $B$. subtilis of our 7PJ-16 strain was also reconfirmed by this approach (Fig. 4). Our study verified that the genome-based analysis could be used as a useful alternative technique in taxonomy of genetic-closely related species, such as the B. subtilis-like organisms [20]. 


\section{Conclusions}

In this study, we report the complete genome of Bacillus sp. strain 7PJ-16 and its final classification status as B. subtilis was further confirmed by the phylogenomic analysis. B. subtilis 7PJ-16 not only could control mulberry fruit sclerotiniose under fields, but stimulate the mulberry seed germination and mulberry seedling growth in greenhouse conditions. In addition, six gene clusters related with biosynthesis of antimicrobial metabolites were identified in the B. subtilis 7PJ-16 genome and it provided us a molecular basis to understand the strain's extraordinary biocontrol capacity against mulberry fruit sclerotiniose. And the 7PJ-16 strain possesses numerous genes related to the synthesis of plant growth-promoting substances, such as indole-3-acetic acid, volatile substances and siderophores. Genome sequencing and analysis of the B. subtilis 7PJ-16 strain does provide valuable information revealing its biological control mechanisms at the genetic level. As such this information has the potential to the application of Bacillus strains as agricultural biocontrol and biofertilizer agents. However, additional studies are needed to assess the safety status and potential health benefits of this strain before it can be applied at the field level.

\section{Nucleotide Sequence Accession Numbers}

The complete genome sequence of $B$. subtilis $7 \mathrm{PJ}-16$ has been deposited in GenBank under accession number CP023409. In addition, this strain has been deposited at the China Center for Type Culture Collection under accession number CCTCC M 2015319. 


\section{Acknowledgments}

The authors acknowledge the financial support of the National Natural Science Foundation of China (31601678), the Fundamental Research Funds for the Central Universities (XDJK2018D020) to Ting Ou, and the Natural Science Foundation of Chongqing (cstc2015jcyjys80001) to Jie Xie.

\section{References}

1. Gray E, Gray RE (1987) Observations on popcorn disease of mulberry in south central Kentucky. Castanea the Journal of the Southern Appalachian Botanical Club 52:47-51

2. Ju WT, Kim HB, Sung GB, Park KY, Kim YS (2016) Mulberry popcorn disease occurrence in Korea region and development of integrative control method. Int J Indust Entomol 33:36-40

3. Kuai YZ, Wu FA (2012) A review on pathogens of mulberry fruit sclerotiniosis and its control technology. Sci Seric (In Chinese) 38:1099-1104

4. Lü RH, Zhao AC, Li J, Wang XL, Yu YS, Lu C, Yu MD (2013a) Biological study of hypertrophy sorosis scleroteniosis and its molecular characterization based on LSU rRNA. Afr J Microbiol Res 7:3405-3411

5. Lü RH, Zhao AC, Yu J, Wang CH, Liu CY, Cai YX, Yu MD (2017) Biological characteristics and epidemiological analysis of the pathogen of hypertrophy sorosis scleroteniosis, Ciboria shiraiana. J Microbiol (In Chinese) 57:388-398

6. Hong SK, Kim WG, Sung GB, Nam SH (2007) Identification and distribution of two fungal species causing sclerotial disease on mulberry fruits in Korea. Mycobiology $35: 87-90$ 
7. Hu JH, Cai YX, Zhou SJ, Zhang JC, Zhang HL, Chen YB, Li PM, Ying GM (2011) Diversity of mulberry sclerotiniose pathogen and ITS analysis. J Ningbo Univ (In Chinese) 24:20-23

8. Whetzel HH, Wolf FA (1945) The cup fungus, Ciboria carunculoides, pathogenic on mulberry fruits. Mycologia 37:476-491

9. Sultana R, Ju HJ, Chae JC, Kim K, Lee KJ (2013) Identification of Ciboria carunculoides RS103V, a fungus causing popcorn disease on mulberry fruits in Korea. Res Plant Dis $19: 308-312$

10. Lü RH, Zhao AC, Jin XY, Du YW, Wu WB, Wang XL, Yu MD (2011) A primary experiment on the control of mulberry fruit sclerotiniosis using herbicide glyphosate. Sci Seric (In Chinese) 37:907-913

11. Lü RH, Ding ZY, Wang XL, Wu WB, Zhao AC, Li J, Yu MD (2013b) An experiment on killing mulberry fruit sclerotiniosis ascospores with the infrared high-temperature thermistor. J Southwest Univ (In Chinese) 35:10-14

12. Ye MQ, Yue HL, Luo GQ, Yang Q, Kuang ZS (2014) Effect of a fungal pathogen, Trichoderma hamatum, on growth and germination of Ciboria carunculoides under laboratory conditions. Pak J Zool 46:1377-1384

13. Sultana R, Kim K (2016) Bacillus thuringiensis C25 suppresses popcorn disease caused by Ciboria shiraiana in mulberry (Morus australis L.). Biocontrol Sci Techn 26:145-162

14. Choudhary DK, Johri BN (2009) Interactions of Bacillus spp. and plants with special reference to induced systemic resistance (ISR). Microbiol Res 164:493-513

15. Gond SK, Bergen MS, Torres MS, James F, White J (2015) Endophytic Bacillus spp. 
produce antifungal lipopeptides and induce host defence gene expression in maize. Microbiol Res 172:79-87

16. Ji XL, Lu GB, Gai YP, Zheng CC, Mu ZM (2008) Biological control against bacterial wilt and colonization of mulberry by an endophytic Bacillus subtilis strain. FEMS Microbiol Ecol 65:565-573

17. Shrestha BK, Karki HS, Groth DE, Jungkhun N, Ham JH (2016) Biological Control Activities of Rice-Associated Bacillus sp. Strains against Sheath Blight and Bacterial Panicle Blight of Rice. Plos One 11:1-18

18. Stein T (2005) Bacillus subtilis antibiotics: structures, syntheses and specific functions. Mol Microbiol 56:845-857

19. Sun GZ, Yao T, Feng CJ, Chen L, Li JH, Wang L (2017) Identification and biocontrol potential of antagonistic bacteria strains against Sclerotinia sclerotiorum, and their growth-promoting effects on Brassica napus. Biol Control 104:35-43

20. Gatson JW, Benz BF, Chandrasekaran C, Satomi M, Venkateswaran K, Hart ME (2006) Bacillus tequilensis sp. nov. isolated from a 2000-year-old Mexican shaft-tomb, is closely related to Bacillus subtilis. Int J Syst Evol Microbiol 56:1475-1484

21. Fox GE, Wisotzkey JD, Jurtshuk JR (1992) How close is close: 16S rRNA sequence identity may not be sufficient to guarantee species identity. Int $\mathrm{J}$ Syst Bacteriol 42:166-170

22. Pan HQ, Li QL, Hu JC (2017) The complete genome sequence of Bacillus velezensis 9912D reveals its biocontrol mechanism as a novel commercial biological fungicide agent. J Biotechnol 247:25-28 
23. Xie J, Ren HS, Tang CM, Zuo WD, Chen J, Huang CS, Wang ZJ, Dai FW, Zhou ZY (2015) Identification of a mulberry endophytic bacterium and its antagonistic activity on Scleromitula shiraiana. Sci Seric (In Chinese) 41:815-824

24. Glickmann E, Dessaux Y (1995) A critical examination of the specificity of the salkowski reagent for indolic compounds produced by phytopathogenic bacteria. Appl Environ Microbiol 61:793-796

25. Xie J, Shu P, Strobel GA, Chen J, Wei JH, Xiang ZH, Zhou ZY (2017) Pantoea agglomerans $\mathrm{SWg} 2$ colonizes mulberry tissues, promotes disease protection and seedling growth. Biol Control 113:9-17

26. Chin CS, Alexander DH, Marks P, Klammer AA, Drake J, Heiner C, Clum A, Cpoeland A, Huddleston J, Eichler EE, Turner SW, Korlach J (2013) Nonhybrid, finished microbial genome assemblies from long-read SMRT sequencing data. Nat Methods 10:563-569

27. Besemer J, Lomsadze A, Borodovsky M (2001) GeneMarkS: a self-training method for prediction of gene starts in microbial genomes. Implications for finding sequence motifs in regulatory regions. Nucleic Acids Res 29:2607-2618

28. Krzywinski M, Schein J, Birol I, Connors J, Gascoyne R, Horsman D, Jones SJ, Marra MA (2009) Circos: an information aesthetic for comparative genomics. Genome Res 19:1639-1645

29. Tamura K, Stecher G, Peterson D, Filipski A, Kumar S (2013) MEGA6:molecular evolutionary genetics analysis version 6.0. Molecular biology and evolution. 30:2725-2729

30. Jasim B, Joseph AA, John CJ, Mathew J, Radhakrishnan EK (2013) Isolation and 
characterization of plant growth promoting endophytic bacteria from the rhizome of Zingiber officinale. Biotech 4:197-204

31. Patagundi BI, Shivasaran CT, Kaliwal BB (2014) Isolation and characterization of cellulose producing bacteria from soil. Int J Curr Microbiol Appl Sci 3:59-69

32. Chen H, Xiao X, Wang J, Wu LJ, Zheng ZM, Yu ZL (2008) Antagonistic effects of volatiles generated by Bacillus subtilis on spore germination and hyphal growth of the plant pathogen, Botrytis cinerea. Biotechnol Lett 30:919-923

33. Chun J, Bae KS (2000) Phylogenetic analysis of Bacillus subtilis and related taxa based on partial gyrA gene sequences. Antonie Van Leeuwenhoek 78:123-127

34. Peypoux F, Bonmatin JM, Wallach J (1999) Recent trends in the biochemistry of surfactin. Appl Microbiol Biotechnol 51:553-563

35. Vanittanakom N, Loeffler W, Koch U, Jung G (1986) Fengycin--a novel antifungal lipopeptide antibiotic produced by Bacillus subtilis F-29-3. J Antibiot 39:888-901

36. Borriss R, Chen XH, Rueckert C, Blom J, Becker A, Baumgarth B, Fan B, Pukall R, Schumann P, Sproer C, Junge H, Vater J, Pühler A, Klenk HP (2011) Relationship of Bacillus amyloliquefaciens clades associated with strains DSM $7^{\mathrm{T}}$ and FZB42 ${ }^{\mathrm{T}}$ : a proposal for Bacillus amyloliquefaciens subsp. amyloliquefaciens subsp. nov. and Bacillus amyloliquefaciens subsp. plantarum subsp. nov. based on complete genome sequence comparisons. Int J Syst Evol Microbiol 61:1786-1801

37. Kenig M, Abraham EP (1976) Antimicrobial activities and antagonists of bacilysin and anticapsin. J Gen Microbiol 94:37-45

38. Khochamit N, Siripornadulsil S, Sukon P, Siripornadulsil W (2015) Antibacterial activity 
and genotypic-phenotypic characteristics of bacteriocin-producing Bacillus subtilis KKU213: Potential as a probiotic strain. Microbiol Res 170:36-50

39. Liu T, Chen YP, Li QJ, Gu ZF (2014) Cloning and functional analyses of TasA, an antimicrobial protein gene from Bacillus pumilus DX01. J Shanghai Jiaotong Univ (In Chinese) $32: 48-52,58$

40. Liu GQ, Kong YY, Fan YJ, Geng C, Peng DH, Sun M (2017) Whole-genome sequencing of Bacillus velezensis LS69, a strain with a broad inhibitory spectrum against pathogenic bacteria. J Biotechnol 249:20-24

41. Chen Y, Gao X, Chen Y, Qin H, Huang L, Han Q (2014) Inhibitory efficacy of endophytic Bacillus subtilis EDR4 against Sclerotinia sclerotiorum on rapeseed. Biol Control 78: $67-76$

42. Lam B, Strobel GA, Harrison L, Lam S (1987) Transposon mutagenesis and tagging of fluorescent Pseudomonas: antimycotic production is necessary for control of Dutch elm disease. Proc Natl Acad Sci 84:6447-6451

43. Zheng ZY, Yang Y, Ren JQ, Zhang MH, Zeng XL (2016) Biological control test of mulberry fruit sclerotiniosis with two kinds of Trichoderma preparations. Sci Seric (In Chinese) 42:168-170

44. Zhang SM, Wang YX, Meng LQ, Li J, Zhao XY, Cao X, Chen XL, Wang AX, Li JF (2012) Isolation and characterization of antifungal lipopeptides produced by endophytic Bacillus amyloliquefaciens TF28. Afr J Microbiol Res 6:1747-1755

45. Torres MJ, Pérez-Brandan C, Sabaté DC, Petroselli G, Erra-Balsells R, Audisio MC (2017) Biological activity of the lipopeptide-producing Bacillus amyloliquefaciens PGPBacCA1 
on common bean Phaseolus vulgaris L. pathogens. Biol Control 105:93-99

46. Cawoy H, Debois D, Franzil L, De-Pauw E, Thonart P, Ongena M (2015) Lipopeptides as main ingredients for inhibition of fungal phytopathogens by Bacillus subtilis/amyloliquefaciens. Microb Biotechnol 8:281-295

47. Dunlap CA, Bowman MJ, Schisler DA (2013) Genomic analysis and secondary metabolite production in Bacillus amyloliquefaciens AS 43.3:A biocontrol antagonist of Fusarium head blight. Biol Control 64:166-175

48. Radhakrishnan R, Lee IJ (2016) Gibberellins producing Bacillus methylotrophicus KE2 supports plant growth and enhances nutritional metabolites and food values of lettuce. Plant Physiology and Biochemistry 109:81-189

49. Dorra BA, Olfa FG, Slim T (2018) Rizhospheric competence, plant growth promotion and biocontrol efficacy of Bacillus amyloliquefaciens subsp. plantarum strain 32a. Biol Control doi:10.1016/j.biocontrol.2018.01.013

50. Rooney AP, Price NP, Ehrhardt C, Swezey JL, Bannan JD (2009) Phylogeny and molecular taxonomy of the Bacillus subtilis species complex and description of Bacillus subtilis subsp. inaquosorum subsp nov. Int J Syst Evol Microbiol 59:2429-2436

51. Cai XC, Liu CH, Wang BT, Xue YR (2017) Genomic and metabolic traits endow Bacillus velezensis $\mathrm{CC} 09$ with a potential biocontrol agent in control of wheat powdery mildew disease. Microbiol Res 196:89-94 
Table 1 The biocontrol efficacies of 7PJ-16 supernatant in the field in 2016

\begin{tabular}{lll}
\hline Treatments & Disease incidence \pm SE $(\%)$ & Biocontrol efficacy \pm SE $(\%)$ \\
\hline Water & $70.22 \pm 2.72 \mathrm{a}$ & - \\
7PJ-16 supernatant (original) & $19.57 \pm 1.60 \mathrm{c}$ & $72.13 \pm 2.28 \mathrm{~b}$ \\
7PJ-16 supernatant (100-fold dilution) & $52.83 \pm 5.45 \mathrm{~b}$ & $24.77 \pm 7.76 \mathrm{c}$ \\
Thiophanate-methyl (1000-fold dilution) & $1.29 \pm 0.13 \mathrm{~d}$ & $98.16 \pm 0.18 \mathrm{a}$ \\
\hline
\end{tabular}

SE, standard error of means

Different letters on each number define groups of treatments that showed significant differences at the $\mathrm{P} \leqslant 0.05$ by one-way analysis of variance (ANOVA) and least significant difference (LSD) tests 
Table 2 The biocontrol efficacies of 7PJ-16 cell suspension and supernatant in the field in 2017

\begin{tabular}{lll}
\hline Treatments & Disease incidence \pm SE $(\%)$ & Biocontrol efficacy \pm SE $(\%)$ \\
\hline Water & $8.73 \pm 0.30 \mathrm{a}$ & - \\
Application once at initial flowering stage & & \\
7PJ-16 suspension $\left(1.0 \times 10^{9} \mathrm{CFU} / \mathrm{mL}\right)$ & $1.37 \pm 0.31 \mathrm{de}$ & $84.33 \pm 3.55 \mathrm{ab}$ \\
7PJ-16 suspension $\left(1.0 \times 10^{8} \mathrm{CFU} / \mathrm{mL}\right)$ & $6.05 \pm 0.49 \mathrm{bc}$ & $30.66 \pm 5.65 \mathrm{~cd}$ \\
7PJ-16 suspension $\left(1.0 \times 10^{7} \mathrm{CFU} / \mathrm{mL}\right)$ & $6.67 \pm 0.42 \mathrm{~b}$ & $23.58 \pm 4.88 \mathrm{~d}$ \\
7PJ-16 supernatant (original) & $1.23 \pm 0.14 \mathrm{e}$ & $85.88 \pm 1.62 \mathrm{a}$ \\
7PJ-16 supernatant $(10$-fold dilution) & $2.28 \pm 0.39 \mathrm{~d}$ & $73.90 \pm 4.44 \mathrm{~b}$ \\
7PJ-16 supernatant $(100-$ fold dilution) & $5.86 \pm 0.63 \mathrm{bc}$ & $32.90 \pm 7.24 \mathrm{c}$ \\
Application twice at initial and full flowering stage & & $87.33 \pm 2.61 \mathrm{a}$ \\
7PJ-16 suspension $\left(1.0 \times 10^{9} \mathrm{CFU} / \mathrm{mL}\right)$ & $1.11 \pm 0.23 \mathrm{e}$ & $39.37 \pm 3.59 \mathrm{c}$ \\
7PJ-16 suspension $\left(1.0 \times 10^{8} \mathrm{CFU} / \mathrm{mL}\right)$ & $5.29 \pm 0.31 \mathrm{c}$ & $16.58 \pm 3.67 \mathrm{~d}$ \\
7PJ-16 suspension $\left(1.0 \times 10^{7} \mathrm{CFU} / \mathrm{mL}\right)$ & $7.28 \pm 0.32 \mathrm{~b}$ & $87.99 \pm 1.31 \mathrm{a}$ \\
7PJ-16 supernatant (original) & $1.05 \pm 0.11 \mathrm{e}$ & $80.34 \pm 1.24 \mathrm{ab}$ \\
7PJ-16 supernatant $(10-$ fold dilution) & $1.72 \pm 0.11 \mathrm{de}$ & $76.68 \pm 4.79 \mathrm{ab}$ \\
7PJ-16 supernatant $(100-$ fold dilution) & $2.04 \pm 0.42 \mathrm{de}$ & \\
Application three times at total flowering stage & & $90.84 \pm 1.41 \mathrm{a}$ \\
7PJ-16 suspension (1.0 $\left.\times 10^{9} \mathrm{CFU} / \mathrm{mL}\right)$ & $0.80 \pm 0.12 \mathrm{e}$ & $90.52 \pm 0.40 \mathrm{a}$ \\
7PJ-16 supernatant (original) & $1.07 \pm 0.03 \mathrm{e}$ & \\
Thiophanate-methyl $(1000-$ fold dilution) & $0.83 \pm 0.04 \mathrm{e}$ & \\
\hline
\end{tabular}

SE, standard error of means

Different letters on each number define groups of treatments that showed significant differences at the $\mathrm{P} \leqslant 0.05$ by one-way analysis of variance (ANOVA) and least significant difference (LSD) tests 
Table 3 Effects of the endophyte 7PJ-16 on mulberry seed germination and growth

\begin{tabular}{lcllll}
\hline Treatments & Dilution time & Germination potential $(\%)$ & Germination rate $(\%)$ & Radicle length $(\mathrm{mm})$ & Plumule length $(\mathrm{mm})$ \\
\hline Kings B medium & - & $55.00 \pm 4.18 \mathrm{de}$ & $71.00 \pm 3.67 \mathrm{~cd}$ & $40.88 \pm 2.70 \mathrm{a}$ & $13.42 \pm 0.94 \mathrm{ab}$ \\
Water & - & $58.00 \pm 2.55 \mathrm{~cd}$ & $73.00 \pm 5.70 \mathrm{~cd}$ & $30.18 \pm 0.70 \mathrm{bc}$ & $11.10 \pm 0.75 \mathrm{~cd}$ \\
7PJ-16 suspension & 0 & $71.00 \pm 3.32 \mathrm{ab}$ & $79.00 \pm 6.40 \mathrm{abc}$ & $32.34 \pm 2.10 \mathrm{bc}$ & $11.09 \pm 0.60 \mathrm{~cd}$ \\
$\left(10^{8} \mathrm{CFU} / \mathrm{mL}\right)$ & 10 & $45.00 \pm 2.24 \mathrm{f}$ & $74.00 \pm 11.55 \mathrm{bcd}$ & $28.76 \pm 1.38 \mathrm{c}$ & $10.99 \pm 0.65 \mathrm{~d}$ \\
& 100 & $65.00 \pm 2.24 \mathrm{bc}$ & $88.00 \pm 3.00 \mathrm{ab}$ & $33.43 \pm 1.57 \mathrm{~b}$ & $11.54 \pm 0.65 \mathrm{bcd}$ \\
& 1000 & $79.00 \pm 1.87 \mathrm{a}$ & $90.00 \pm 3.16 \mathrm{a}$ & $32.55 \pm 0.99 \mathrm{bc}$ & $10.26 \pm 0.40 \mathrm{~d}$ \\
7PJ-16 cell-free & 0 & $54.00 \pm 3.67 \mathrm{def}$ & $71.00 \pm 3.67 \mathrm{~cd}$ & $40.32 \pm 2.62 \mathrm{a}$ & $13.26 \pm 1.40 \mathrm{abc}$ \\
supernatant & 10 & $46.00 \pm 2.45 \mathrm{ef}$ & $61.00 \pm 4.58 \mathrm{~d}$ & $43.71 \pm 1.89 \mathrm{a}$ & $15.26 \pm 0.82 \mathrm{a}$ \\
& 100 & $67.00 \pm 1.22 \mathrm{bc}$ & $83.00 \pm 3.39 \mathrm{abc}$ & $40.08 \pm 2.20 \mathrm{a}$ & $11.81 \pm 1.08 \mathrm{bcd}$ \\
& 1000 & $73.00 \pm 6.04 \mathrm{ab}$ & $84.00 \pm 2.45 \mathrm{abc}$ & $39.33 \pm 2.35 \mathrm{a}$ & $14.94 \pm 0.69 \mathrm{a}$ \\
\hline
\end{tabular}

Note: Values are the results of the mean plus standard error, and different letters in the same

column indicate a significant difference at $\mathrm{P} \leqslant 0.05$ by one-way analysis of variance (ANOVA) and least significant difference (LSD) tests 
Table 4 Genomic features of Bacillus sp.7PJ-16 and related members of the Bacillus genus

\begin{tabular}{ccccccc}
\hline & Bacillus & B. tequilensis & B. subtilis & B. subtilis & B. amyloliquefaciens & B. velezensis \\
Features & sp.7PJ-16 & FJAT-14262a & 168 & Bsn5 & L-S60 & 9912D \\
\hline Genome size (bp) & $4,209,045$ & $4,038,551$ & $4,215,606$ & $4,093,599$ & $3,903,017$ & $4,241,576$ \\
G+C content (\%) & $43.28 \%$ & $43.71 \%$ & $43.50 \%$ & $43.85 \%$ & $46.67 \%$ & $45.99 \%$ \\
Plasmid & 2 & - & - & - & - & 1 \\
rRNA operons & 30 & 6 & 30 & 31 & 26 & 27 \\
tRNA operons & 86 & 66 & 86 & 83 & 91 & 86 \\
Total predicted CDS & 4,492 & 3,919 & 4,174 & 4,177 & 3,909 & 4,436 \\
\hline
\end{tabular}

CDS a: Coding DNA Sequences 
Table 5 Identification of gene clusters potentially involved in antimicrobial metabolite synthesis by B. subtilis 7PJ-16

\begin{tabular}{lllll}
\hline Clusters $^{\mathrm{a}}$ & Types $^{\mathrm{b}}$ & Position $^{\mathrm{c}}$ & Metabolite $^{\mathrm{d}}$ & Function $^{\mathrm{e}}$ \\
\hline 1 & Nrps & $391449-456840$ & Surfactin & Antivirus, antimycoplasma, antitumor \\
2 & Terpene & $1197446-1218258$ & Unknown & Unknown \\
3 & Lantipeptide & $1765179-1805797$ & Unknown & Unknown \\
4 & Nrps & $1918705-1975814$ & Fengycin & Antifungal \\
5 & Terpene & $2053475-2075397$ & Unknown & Unknown \\
6 & T3pks & $2254102-2295199$ & Unknown & Unknown \\
7 & Nrps & $3228426-3278167$ & Bacillibactin & Accumulate and take up iron ions \\
8 & Lantipeptide & $3426439-3452493$ & Subtilin & Antibacterial $\left(\mathrm{G}^{+}\right)$ \\
9 & Lantipeptide & $3813741-3835352$ & Subtilosin A & Antibacterial $\left(\mathrm{G}^{+}\right)$ \\
10 & Nrps & $3838655-3880073$ & Bacilysin & Antibacterial and Candida albicans \\
\hline
\end{tabular}

${ }^{\text {a }}$ Clusters identified using the default settings of antiSMASH 4.0

${ }^{\mathrm{b}}$ Classes of gene cluster according to antiSMASH 4.0

${ }^{\mathrm{c}}$ Location of gene clusters in the B. subtilis 7PJ-16 genome

${ }^{\mathrm{d}}$ Secondary metabolites potentially produced based on the gene clusters

${ }^{\mathrm{e}}$ Bioactive function of metabolites synthesized by the gene clusters 
Table 6 Representative genes of B. subtilis 7PJ-16 likely involved in plant growth promotion

\begin{tabular}{|c|c|c|c|}
\hline Gene & Position & Protein & Description \\
\hline$d h b F$ & $3,248,426-3,255,562$ & $\begin{array}{l}\text { 2,3-dihydroxybenzoate-glycine-threonine } \\
\text { trimeric ester }\end{array}$ & Bacillibactin biosynthesis \\
\hline$d h b B$ & $3,255,582-3,2565,20$ & Isochorismatase & Bacillibactin biosynthesis \\
\hline$d h b E$ & $3,256,548-3,258,167$ & 2,3-dihydroxybenzoate-AMP ligase & Bacillibactin biosynthesis \\
\hline$d h b C$ & $3,258,196-3,259,392$ & Isochorismate synthase & Bacillibactin biosynthesis \\
\hline$d h b A$ & $3,259,418-3,260,203$ & $\begin{array}{l}\text { 2,3-dihydroxybenzoate } \\
\text { dehydrogenase }\end{array}$ & Bacillibactin biosynthesis \\
\hline alsD & $3,696,405-3,697,184$ & Acetolactate decarboxylase & Acetoin biosynthesis \\
\hline als $S$ & $3,697,234-3,698,949$ & Acetolactate synthase & Acetoin biosynthesis \\
\hline alsR & $3,699,104-3,700,012$ & Transcriptional regulator & Regulator of the alsDS operon \\
\hline$b d h A$ & $704,601-705,641$ & Acetoin reductase & 2,3-butanediol biosynthesis \\
\hline treP & $900,870-902,282$ & Phosphotransferase & Trehalose biosynthesis \\
\hline $\operatorname{treA} / C$ & $902,353-904,038$ & Trehalose-6-phosphate hydrolase & Trehalose biosynthesis \\
\hline treR & $904,059-904,775$ & Transcriptional regulator (GntR family) & Trehalose biosynthesis \\
\hline phy & $2,241,654-2,242,802$ & Phytase & Phosphate availability \\
\hline$b g l S$ & $1,924,777-1,926,225$ & Endo-1,4-beta-glucanase & Cellulose degradation \\
\hline bglC & $3,998,347-3,999,057$ & Endo-beta-1,3-1,4 glucanase & Cellulose degradation \\
\hline xynA & $2,011,681-2,012,322$ & Endo-1,4-beta-xylanase & Xylanase degradation \\
\hline$x y n D$ & $1,928,213-1,929,616$ & Endo-1,4-beta-xylanase & Xylanase degradation \\
\hline$y h c X$ & $1,044,946-1,046,487$ & Amidohydrolase & Trp-dependent IAA synthesis \\
\hline dhaS & $2,061,925-2,063,397$ & Aldehyde dehydrogenase & Trp-dependent IAA synthesis \\
\hline
\end{tabular}



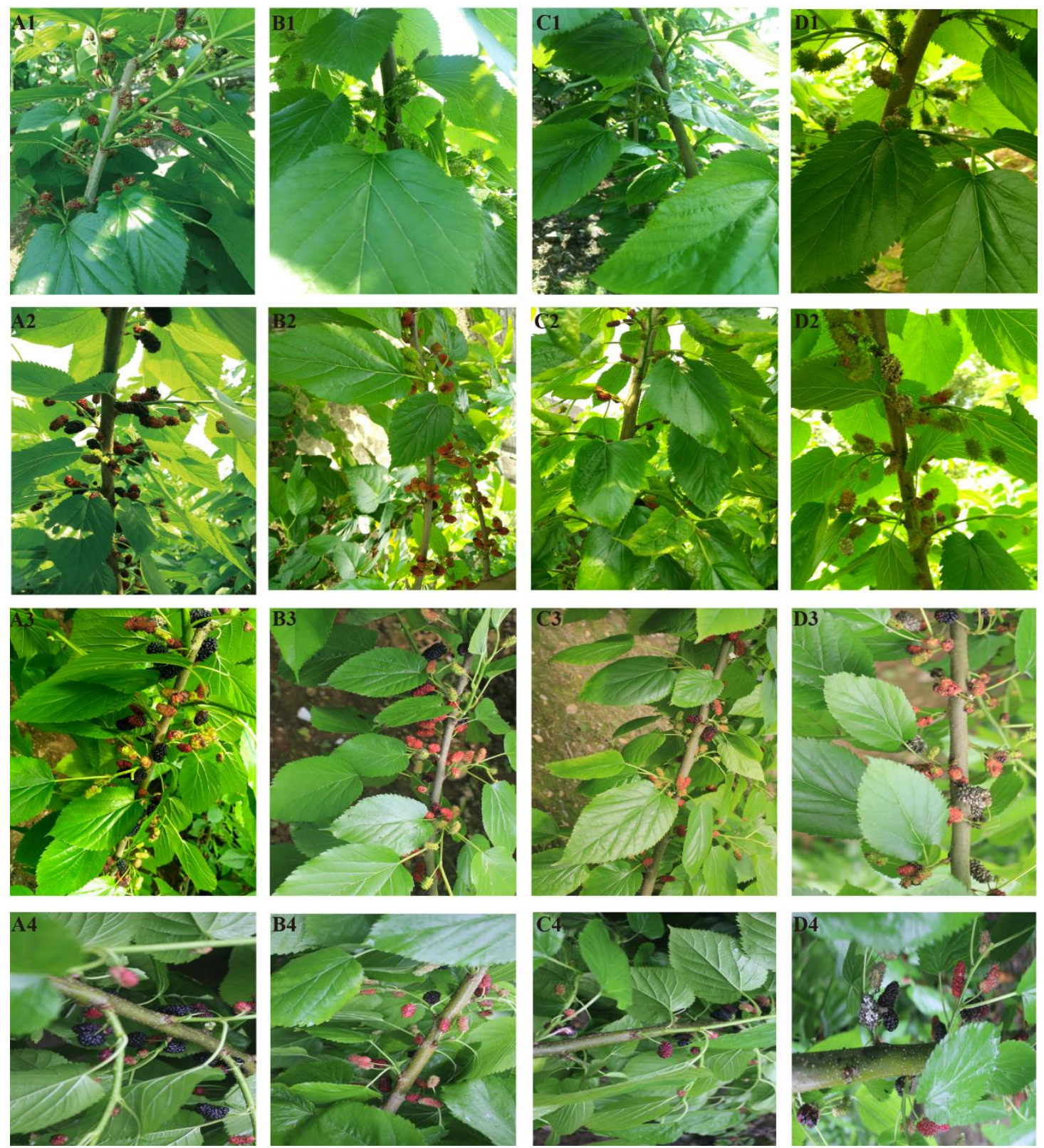

Fig. 1 Biocontrol efficacies of the endophyte 7PJ-16 on mulberry fruit sclerotiniose after the third application in the fields in 2017. (A) 7PJ-16 cell suspension; (B) thiophanate-methyl; (C) 7PJ-16 supernatant; (D) water control. The number $1 \sim 4$ respectively represent the control efficacies at 7 , 15,22 and 30 days after treatment 

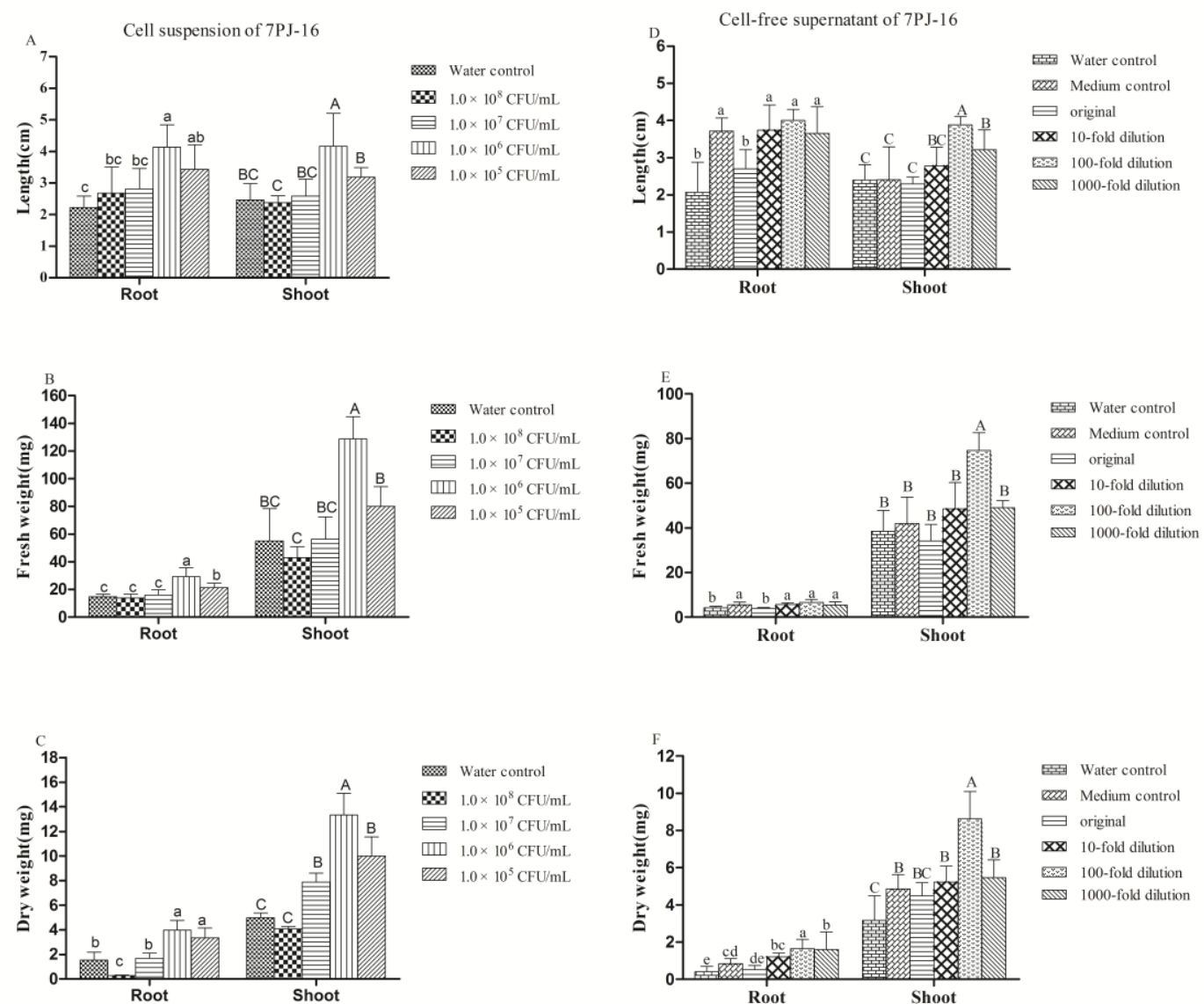

Fig. 2 The effects of 7PJ-16 cell suspension (A C) and 7PJ-16 cell-free supernatant (D F) on the growth of mulberry seedlings 45 days after treatment. (A) and (D) root and shoot lengths; (B) and (E) root and shoot fresh weights; $(\mathrm{C})$ and $(\mathrm{F})$ root and shoot dry weights. Bars with the different letters indicate a significant difference between means by one-way analysis of variance (ANOVA) and least significant difference $(\mathrm{LSD})$ tests $(\mathrm{P} \leqslant 0.05)$. Error bars indicate $\pm \mathrm{SD}$ of five replicates 

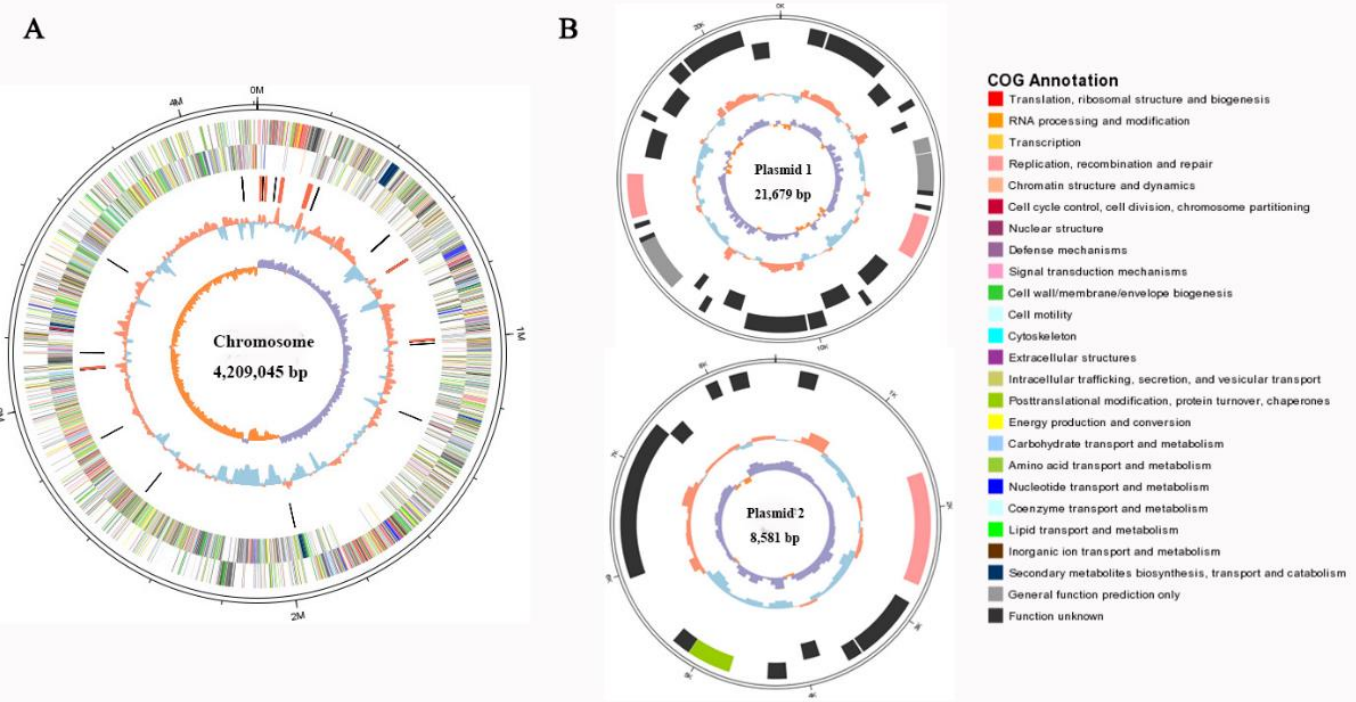

Fig. 3 Circular genome maps of the Bacillus sp. 7PJ-16 genome. (A) circular chromosome; (B) plasmids. From outside to inside: (1) size of the complete genome; (2-3) predicted protein-coding genes on the + and - strands, with different colors representing different COG functional classifications; (4) rRNA (red) and tRNA (black); (5) $\mathrm{G}+\mathrm{C}$ content, with $>43.28 \% \mathrm{G}+\mathrm{C}$ indicated in red and $\leq 43.28 \% \mathrm{G}+\mathrm{C}$ in blue; (6) $\mathrm{G}+\mathrm{C}$ skew, with $\mathrm{G} \%>\mathrm{C} \%$ in purple and $\mathrm{G} \%<$ $\mathrm{C} \%$ in orange 


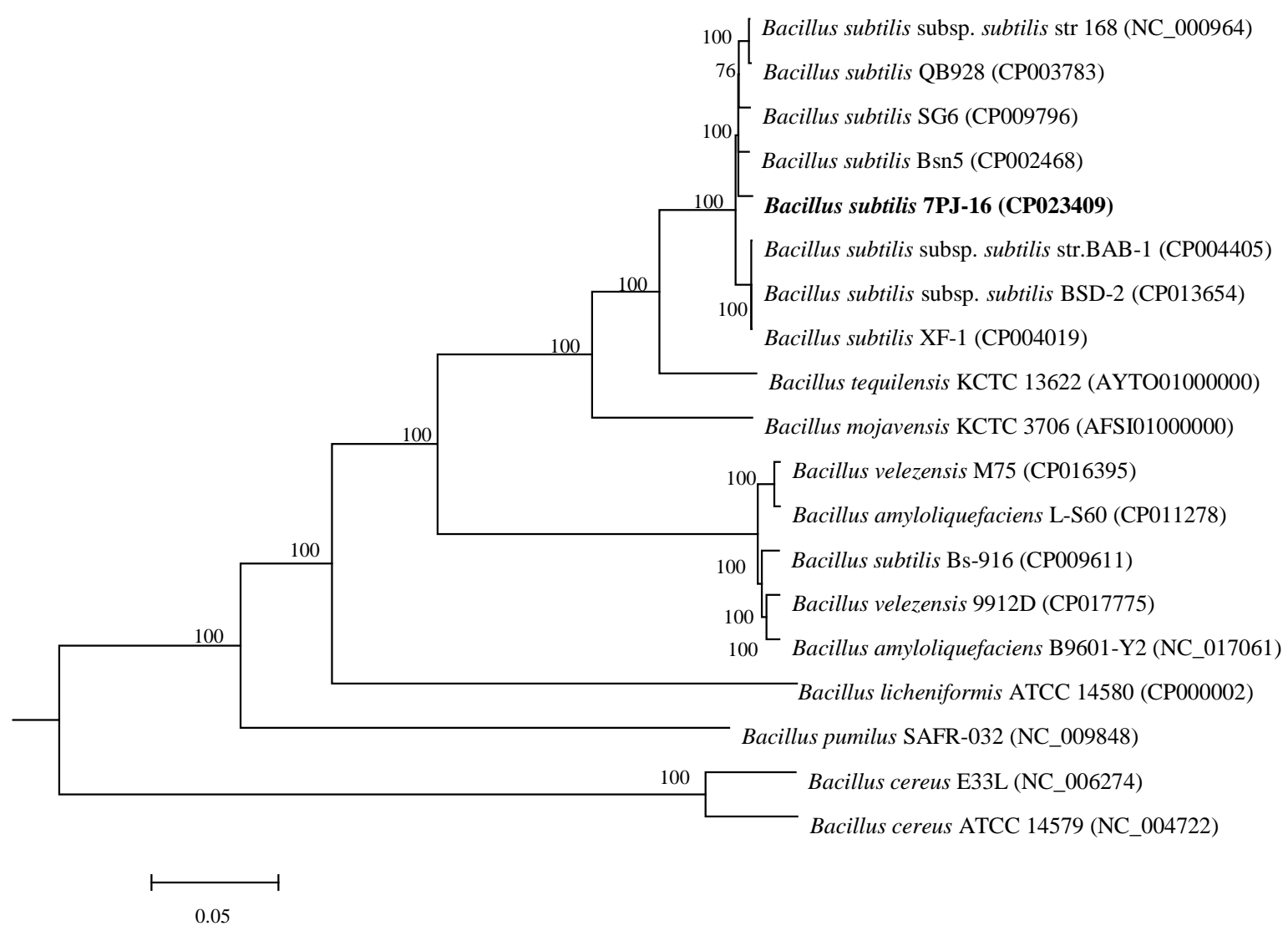

Fig. 4 Phylogenetic tree of Bacillus sp. 7PJ-16 based on the core genomes of 18 representative

Bacillus strains. The percentages at the nodes indicate the levels of bootstrap support based on neighbor-joining analyses of 1,000 resampled data sets 

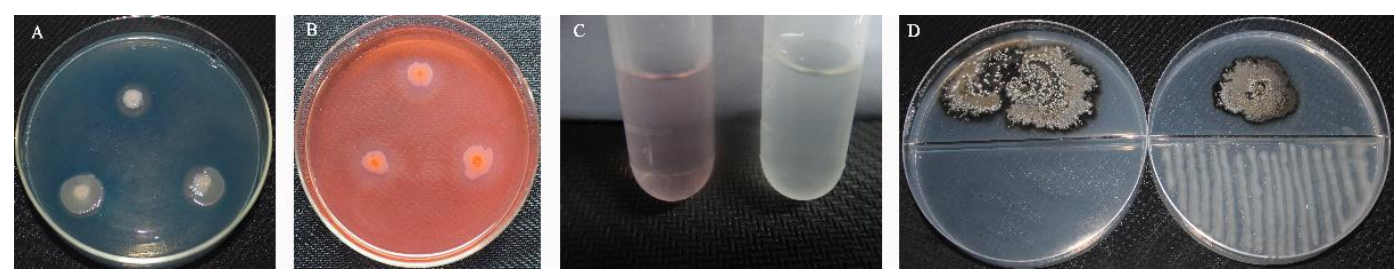

Fig. 5 Secretions of B. subtilis 7PJ-16. (A) iron-siderophore: the zone on chrome Azurol-S medium; (B) cellulase: the zone on carboxymethylcellulose medium; (C) indole acetic acid: left, IAA produced following 7PJ-16 inoculation of PDB medium supplemented with L-tryptophan, and right, non-inoculated PDB medium; (D) volatile compounds: left, PDA medium inoculated with Scleromitrula shiraiana, and right, PDA medium inoculated with Scleromitrula shiraiana and the antagonistic bacterium 7PJ-16 


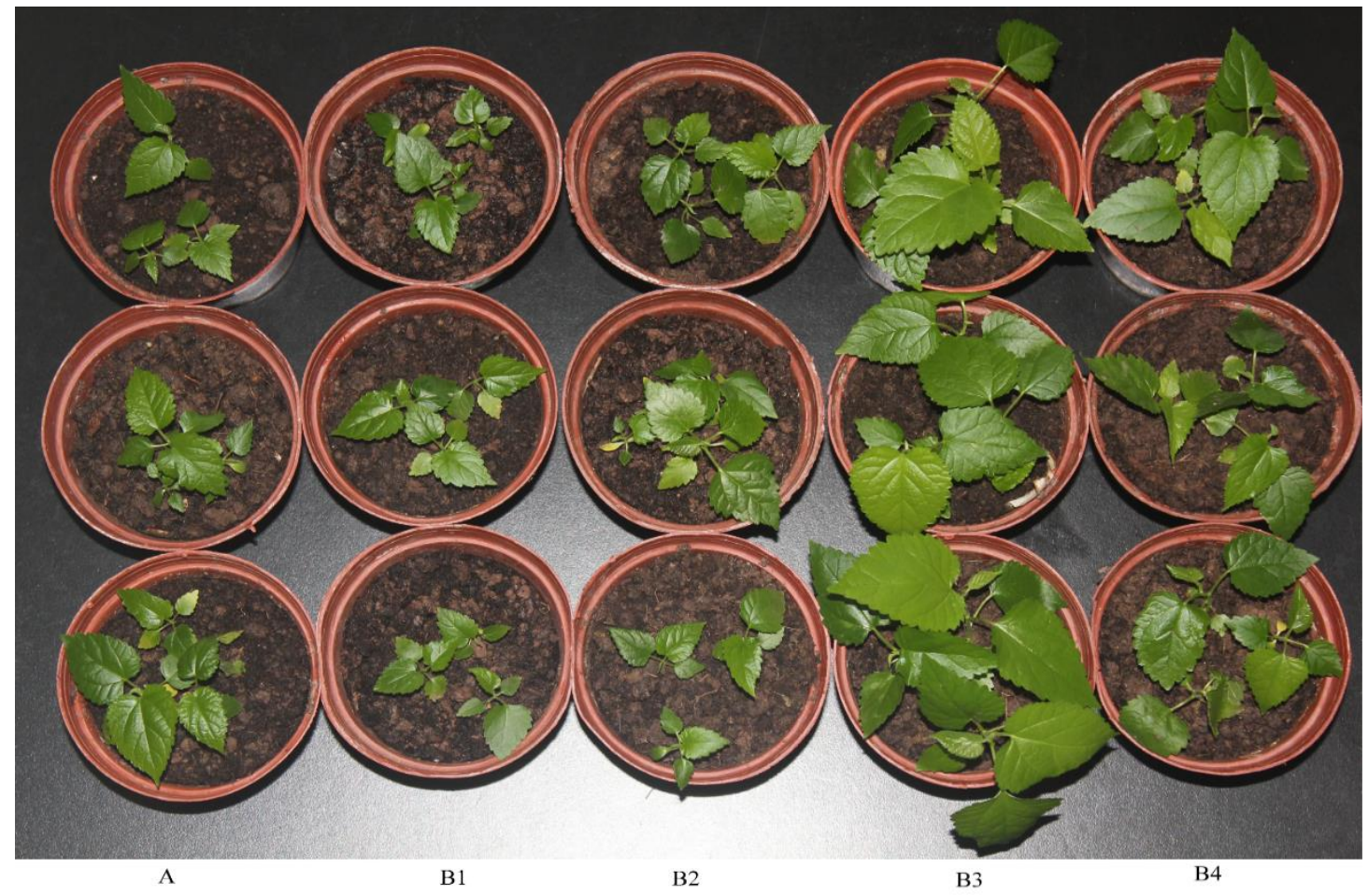

Fig. S1 The effects of 7PJ-16 cell suspension on the growth of mulberry seedlings 45 days after treatment in pots. (A) water control (CK); (B1-B4) 7PJ-16 cell suspension $\left(1.0 \times 10^{8}, 1.0 \times 10^{7}\right.$, $\left.1.0 \times 10^{6}, 1.0 \times 10^{5} \mathrm{CFU} / \mathrm{mL}\right)$ 


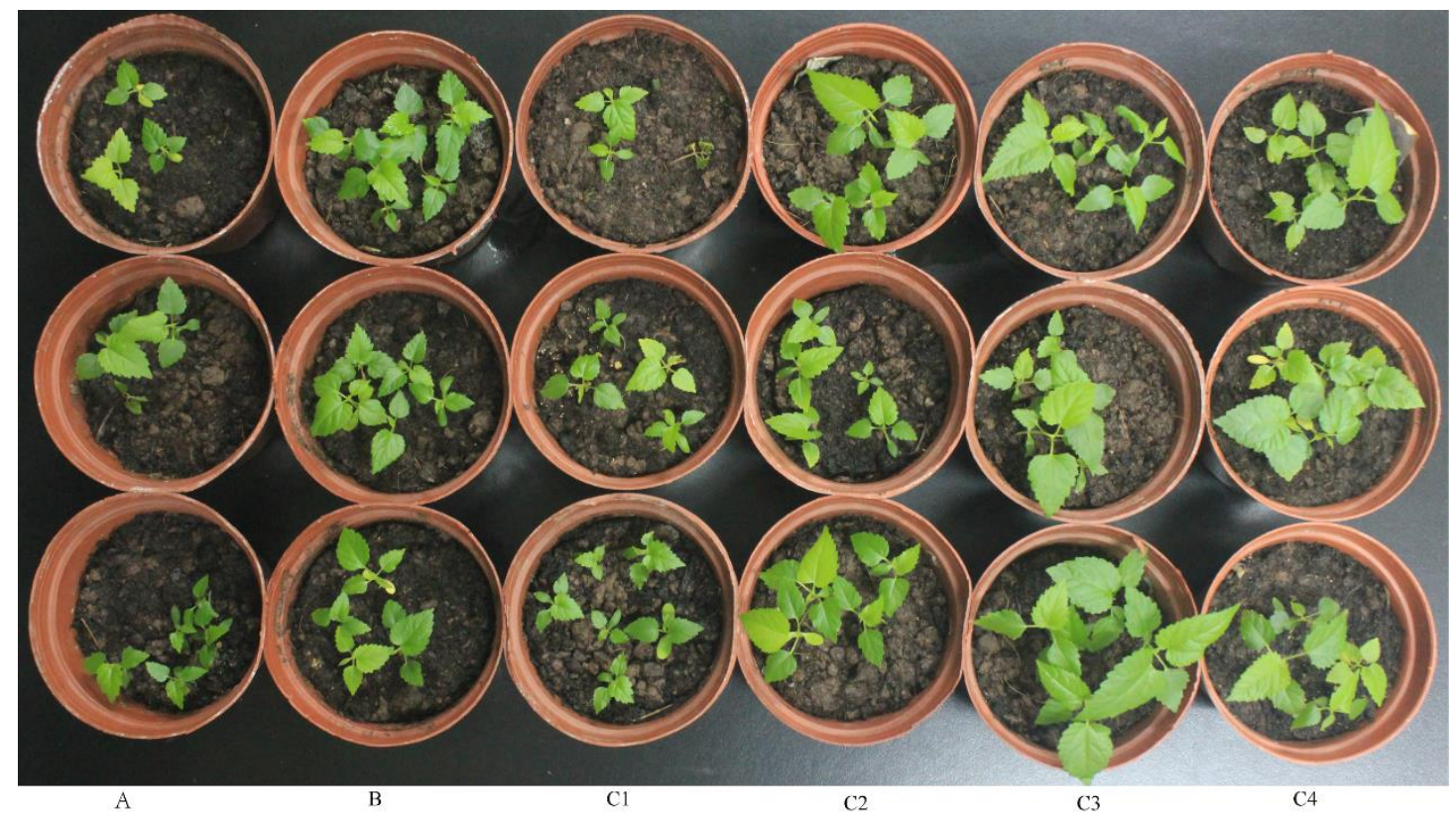

Fig. S2 The effects of 7PJ-16 cell-free supernatant on the growth of mulberry seedlings 45 days after treatment in pots. (A) water control (CK1); (B) medium control (CK2); (C1-C4) 7PJ-16 supernatant (original, 10-fold, 100-fold and 1000-fold dilution) 